\title{
Assessment of Socio Demographic Characteristics on Uptake of Tuberculosis Screening by Community Members in Meru County, Kenya
}

\author{
Martin N. Njiru ${ }^{1,2,3} \quad$ G Otieno $^{2} \quad$ J. Kirui $^{2} \quad$ A. Yoos ${ }^{3}$ \\ 1. Ministry of Health and Sanitation Kitui County P.O. Box 22-90200 Kitui,Kenya \\ 2. Kenyatta University P.O. Box 43844-00100 Nairobi, Kenya \\ 3. Improving Public Health Management for Action (IMPACT), Kenya
}

\begin{abstract}
The trend in tuberculosis in Kenya is worrying. TB is the fourth leading cause of death. In 201581,518 cases of TB were identified and treated. The Kenya prevalence survey of 2015-2016 found that estimated prevalence is $558 / 100,000$ way above the WHO estimate of $233 / 100,000$. The objective of the study was to determine the effect of socio- demographics characteristics on tuberculosis screening among community members in Tigania East of Meru County. The study design used was cross-sectional survey and targeted 440 household drawn from the five wards randomly and proportionately selected. Key informant interviews and focus group discussions were used to collect qualitative data. Qualitative data was analysed thematically. Quantitative data was analysed using descriptive statistics and inferential statistics using SPSS version 26. The study found out that there were statistically significant association between TB screening and religion $\left(X^{2}=13.103\right.$, df 3; $p$ value $=0.004$, $)$, monthly income $\left(\mathrm{X}^{2}=14.970\right.$, df 6; $\mathrm{p}$ value $=0.020$. The study concluded that religion and monthly income of community members of Tigania East were associated with TB screening.
\end{abstract}

Keywords; Socio demographic, Uptake of TB screening, Community members.

DOI: $10.7176 / \mathrm{JBAH} / 10-22-05$

Publication date: November $30^{\text {th }} 2020$

\section{Introduction:}

Global Tuberculosis Report (2013) observe that majority (95\%) of the deaths in developing countries are caused by tuberculosis infections. With increased number of the population in developing countries cases of TB infections have been on the rise annually resulting to increased mortality rates by $95 \%$. Tuberculosis is considered by WHO (2018) to be one of the severe infectious disease that is caused by a combination of mycobacterium genus. Tuberculosis (TB) infections can be transmitted from one patient to another if not diagnosed or detected in advance. It is approximated by WHO (2018) that more than 50\% of TB infected patients were infecting an average of 1015 individuals annually. Despite various strategies adopted by ministry of health from one country to another, it is observed that most of the TB patients do not complete treatment and have little information on the causes and its transmission (Toczek, Cox, Cros, Cooke \& Ford, 2013).Non-adherence to TB treatment and high defaulter rates among patients is attributed to increased mortality rates in developing countries. Multi-drug resistance tuberculosis is one of the common factors that has resulted to high costs of managing TB patients in Africa (Kandel, Mfenyana, Chandia \&Yogeswaran, 2014).

Journal of Biology, Agriculture and Healthcare

The objective of the study was to determine the effect of socio- demographics characteristics on tuberculosis screening among community members in Tigania East of Meru County. Tigania East is the only Sub-county that reported suspected cases of suspected Xtra drug resistant TB (XDR-TB) cases in Meru among the nine sub counties (TIBU report, 2018). Sitienei et al (2013) assert that socio-demographics and Lack knowledge are considered to be some of the factors that undermine the uptake of tuberculosis screening thus increased mortality rates of TB patients. Malinga (2019) conducted a study on tuberculosis (TB) screening compliance rates and treatment completion among international students at the University of Kentucky. When screening rates were compared by gender, the study found out there was no significant difference between male and females $(\mathrm{p}=0.495)$. Jewett et al., (2016) states that risk of exposure to TB in various settings for example hospitals, prisons and shelter homes. Students can be more exposed to TB when volunteering, researching and travelling (Jewett et al., 2016). Medical students are at higher danger of exposure to TB and are required to do annual screening for TB.

World Health Organization report that death rates attributed to TB infections are increasing among community members annually due to inadequate knowledge about TB infections. Moreover, WHO (2018) point out that the low levels of knowledge on, and poor attitudes towards TB screening among community members in Kenya has persisted despite the efforts of the ministry of health and Non-governmental organizations to educate and encourage community members to embrace the practice. Further, the study noted that non-adherence to tuberculosis treatment is increasing mortality rates by $7 \%$ annually. If this continues, more community members will continue suffering from latent and active TB thus resulting to increased mortality rates that could have been 
avoided though voluntary TB screening. This study therefore sought to assess the effect of socio demographic characteristics on uptake of TB screening in Tigania East.

\section{Methodology}

The study adopted cross-sectional research design using both quantitative and qualitative approaches. The crosssectional research design was appropriate because it explores and describes the relationship between variables in their natural setting without manipulating them. This study was limited to Tigania East of Meru County, Kenya. Tigania East which is an administrative sub-County of Meru is considered appropriate areas of study based on the high cases of tuberculosis reported by the Ministry of Health (2018). The study is conducted in Tigania East of Meru County.

The study population is about $60 \%$ of the population are of ages 18 years and above (KNBS). They were about 104,442 persons. These are both male and females. The study population of consisted of 174,121 persons. This is the estimated population of Tigania East by 2018 according to 2009 census projection (KNBS, 2009). The Sub County has five wards. It's in Tigania East Constituency. The respondents comprised of 398 households' members in Tigania East and 45 health workers from public health facilities in Tigania East. The unit of analysis was household members in Tigania East in Meru County while unit of observation was households in Tigania East in Meru County.The inclusion criteria was household members in Tigania East in Meru County who were willing to take part in the study were included. The study considered respondents aged more than 18 years to be appropriate. Respondents residing in the County for the past one year was considered appropriate in this study.

The exclusion criteria were households' members in Tigania East in Meru County unwilling to give consent to the study participation. The study did not consider respondents aged below 18 years. Respondents residing in the county for less than one year were not be included in this study.

The sample size of this study was 440 household respondents as shown in Table 3.1 Israel formula (2009) was used to determine the ideal sample size. Respondents of this study was household members. Israel (2009) formula was used in the form:

\section{Journal of Biology, Agriculture and Healthcare}

$$
\begin{aligned}
& \mathrm{n}=\mathrm{N} /\left(\mathbf{1}+\mathrm{N}(\llbracket \mathrm{e}) \rrbracket^{2}\right) \text { Where: } \mathrm{n} \text { is the sample size, } \mathrm{N} \text { is the target population size, e is the allowable error }(0.05) . \\
& \mathrm{n}=\frac{104,442}{1+104,442(0.05)^{2}} \\
& =400 \text { Household Members and added } 10 \% \text { to cater for drop-out and incomplete questionnaire for a }
\end{aligned}
$$
total of 440 respondents

Table 1 Sampling Frame.

\begin{tabular}{|l|l|l|l|l|}
\hline Ward & Population & Household & Target population & Sample Size \\
\hline Muthara & 43,204 & 8,641 & 25,923 & $\mathbf{9 9}$ \\
\hline Karama & 27,741 & 5,549 & 16,645 & $\mathbf{6 4}$ \\
\hline Kiguchwa & 21,223 & 4,245 & 12,734 & $\mathbf{4 9}$ \\
\hline Mikinduri & 37,412 & 7,483 & 22,448 & $\mathbf{8 6}$ \\
\hline Thangatha & 44,490 & 88,98 & 26,694 & $\mathbf{1 0 2}$ \\
\hline Total & $\mathbf{1 7 4 , 0 7 0}$ & $\mathbf{3 4 , 8 0 8}$ & $\mathbf{1 0 4 , 4 4 2}$ & $\mathbf{4 0 0}$ \\
\hline
\end{tabular}

\section{Source: County Bureau of Statistics (2019)}

Respondents of the study were selected using simple random sampling technique. This method of sampling involves giving a number to every member subject or member of accessible population, placing the numbers in a container and picking any number at random. The subjects corresponding to the numbers picked were included in the sample. The respondents were household members from Tigania East.

Questionnaires with open and closed questions were used to collect data from household members in Tigania East. Questionnaires were preferred due to their ability to capture respondent opinions in a structured manner and in written form for future reference. Further, they will enable the respondents to answer questions freely and frankly even on sensitive issues. In addition, they provide uniformity in answering questions allowing a great degree of comparison because the items are framed in the same format. Items of the questionnaire were measured using a Likert point scale where 4 represents strongly agree while 1 represents strongly disagree.

\section{Journal of Biology, Agriculture and Healthcare}

Focus groups discussions was held with community leaders in Tigania East. The group comprised of 5 to 8 informers and lasted for a minimum of 45 and a maximum of 1 hour. Information related to TB infections sought and evaluated in relation to that given by household Key health workers who are knowledgeable on tuberculosis were interviewed. These are County TB Coordinator, Sub County Clinical Officer, Sub County Laboratory Technologist, Sub County Public Health Officer, Sub County Public Health Nurse, Sub-county TB Coordinator Tigania East and Sub-county Medical Officer of Health in Tigania East.

Content validity which was employed by this study as a measure of the degree to which data collected using 
a particular instrument represents a specific domain or content of a particular concept. The researcher was selected pretest sample of $10 \%$ as recommended by Fisher (2010). Feedback from pretest sample was used to modify questions of the research instrument in order to measure what is expected to be measured. The study used Cronbach's alpha coefficient to test internal consistence of the instrument. Cronbach alpha value of 0.7 was used as the cutoff point as recommended by (Guest, 2018) to suggest reliability of the variables of the study. The overall value was 0.8 for the all the variables.

To analyze the data, the Statistical Package for Social Sciences, (SPSS version 24) software was used. The data collected in the research was sorted, edited, coded, keyed and classified on the basis of similarity and then tabulated. Descriptive statistics was used to analyze data and explain the findings. To permit quantitative analysis, data was converted into numerical codes representing attributes or measurement of variables. Descriptive statistics such as frequency distributions, percentages and frequency were used to summarize and relate variables which was attained from the study. The study adopted inferential statistics such as chi square.

Before data collection, the researcher sought permission from the Kenyatta University and National Commission for Science, Technology and Innovation. Approval from Meru County Health Deptarment was sought. Responsibility to the respondents was to include voluntary participation and informed consent prior to participation.

To ensure the participants was not prejudiced, simple language and statements was used to describe the aim of the research and its procedures. Responsibility to the profession was include accuracy in analysis, presentation and reporting of the study findings. Confidentiality and anonymity of the respondents was guaranteed. For objectivity purposes of scientific reaserch, stakeholders were informed and the objective of the research explained to ehnance willingness and high response rates from the respondents. Finally, respondents was assured about publication of final report.

\section{Results}

A total of 440 household questionnaires were distributed and 425 questionnaires were returned for a response rate of $96.5 \%$. Table 2 summarizes socio-demographic characteristics of respondents. From the results $265(62.4 \%)$ were of the age 35-60 and 59(13.9\%) were of the age 60 and above. The study found out 295(69\%) were married monogamous and $16(4 \%)$ were Divorced, Majority of the respondents $234(55 \%)$ indicated that they had primary level education, $22(5 \%)$ had university level of education ,22(5\%) had diploma level of education.

The study found out that $181(43 \%)$ were farmer and $14(3 \%)$ others. The study finally found out that $281(66 \%)$ of the households earned less than 10,000 and 6(1.4\%) had no monthly income

\section{Journal of Biology, Agriculture and Healthcare}

Table 2 Social Demographic Characteristics of Respondents

\begin{tabular}{|c|c|c|c|}
\hline \multicolumn{2}{|c|}{ Social Demographic } & $\mathrm{N}$ & $\%$ \\
\hline \multirow[t]{3}{*}{ Age } & $18-34$ & 101 & 23.8 \\
\hline & $35-60$ & 265 & 62.4 \\
\hline & $60+$ & 59 & 13.9 \\
\hline \multirow[t]{4}{*}{ Religion } & Catholic & 136 & 32 \\
\hline & Protestant & 280 & 65.9 \\
\hline & Muslim & 3 & 0.7 \\
\hline & None & 6 & 1.4 \\
\hline \multirow[t]{5}{*}{ Education } & None & 23 & 54 \\
\hline & Primary & 234 & 55.1 \\
\hline & Secondary & 124 & 29.2 \\
\hline & University & 22 & 5.2 \\
\hline & Diploma & 22 & 5.2 \\
\hline \multirow{5}{*}{$\begin{array}{l}\text { Main } \\
\text { Occupation }\end{array}$} & Employed/salaries & 36 & 8.5 \\
\hline & Farmers & 181 & 42.6 \\
\hline & Business/Self employed & 100 & 23.5 \\
\hline & Unemployed & 94 & 22.1 \\
\hline & Others & 14 & 3.3 \\
\hline \multirow{7}{*}{$\begin{array}{l}\text { Monthly } \\
\text { income }\end{array}$} & Less than 10,000 & 281 & 66.1 \\
\hline & Between 10,000-20,000 & 90 & 21.2 \\
\hline & Between 20,000-30,000 & 19 & 4.5 \\
\hline & Between $30,000-40,000$ & 11 & 2.6 \\
\hline & Between 40,000-50,000 & 10 & 2.4 \\
\hline & Over 50,0000 & 8 & 1.9 \\
\hline & None & 6 & 1.4 \\
\hline
\end{tabular}


The proportion of respondents who have been screened is presented in figure 1. Majority of the respondents $68 \%(n=288)$ stated that they have never been screened for TB while $32 \%(n=137)$ stated that they have been tested for TB.

\section{TB Screening}

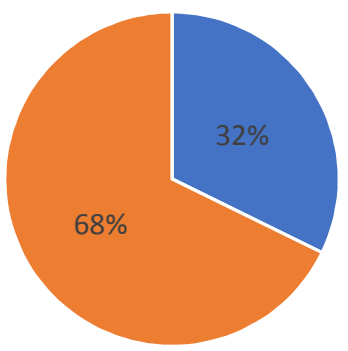

\section{- Screened $\quad$ Not Screened}

\section{Figure 1 Uptake of Tuberculosis Screening}

The result in Table 3 found out that the association between religion and TB screening was statistically significant at $5 \%$ level of significance ( $\mathrm{p}$ value $=0.004<0.05, \mathrm{X}^{2}=13.103$, df 3 ), and the association of monthly income and TB screening was statistically significant at $5 \%$ level of significance ( $p$ value $=0.020<0.05, X^{2}=14.970$, df 6). The rest of the socio demographic parameters that's; age, marital status and education level were not statistically significant.

Journal of Biology, Agriculture and Healthcare

Table 3 Social Demographic characteristics influencing uptake of TB screening

\begin{tabular}{|c|c|c|c|c|c|c|}
\hline Variable & & \multicolumn{2}{|c|}{ Dependent Variable } & \multicolumn{3}{|c|}{ Statistical Significance } \\
\hline \multirow[t]{2}{*}{ Social Demographic } & & Screened & Not Screened & $\mathrm{P}$ value & $\mathrm{X}^{2}$ & $\mathrm{df}$ \\
\hline & & $\mathrm{N} \%$ & $\mathrm{~N} \%$ & \multirow{4}{*}{.071} & \multirow{4}{*}{5.287} & \multirow{4}{*}{2} \\
\hline \multirow[t]{3}{*}{ Age } & $18-34$ & $27(19.7 \%)$ & $74(25.7 \%)$ & & & \\
\hline & $35-60$ & $96(70.1 \%)$ & $169(58.7 \%)$ & & & \\
\hline & $60+$ & $14(10.2 \%)$ & $45(15.6 \%)$ & & & \\
\hline \multirow[t]{5}{*}{ Religion } & \multirow[b]{2}{*}{ Catholic } & $\mathrm{N} \%$ & $\mathrm{~N} \%$ & \multirow{5}{*}{.004} & \multirow{5}{*}{13.103} & \multirow{5}{*}{3} \\
\hline & & $58(42.3 \%)$ & $78(27.1 \%)$ & & & \\
\hline & Protestant & $79(57.7 \%)$ & $201(69.8 \%)$ & & & \\
\hline & Muslim & $0(0 \%)$ & $3(1 \%)$ & & & \\
\hline & None & $0(0 \%)$ & $6(2.1 \%)$ & & & \\
\hline \multirow[t]{6}{*}{ Level of Education } & \multirow[b]{2}{*}{ None } & $\mathrm{N} \%$ & $\mathrm{~N} \%$ & \multirow{6}{*}{.144} & \multirow{6}{*}{6.856} & \multirow{6}{*}{4} \\
\hline & & $6(4.4 \%)$ & $17(5.9 \%)$ & & & \\
\hline & Primary & $66(48.2 \%)$ & $168(58.3 \%)$ & & & \\
\hline & Secondary & $50(36.5 \%)$ & $74(25.7 \%)$ & & & \\
\hline & University & $9(6.6 \%)$ & $13(4.7 \%)$ & & & \\
\hline & Diploma & $6(4.4 \%)$ & $16(5.4 \%)$ & & & \\
\hline \multirow[t]{6}{*}{ Main Occupation } & \multirow[b]{2}{*}{ Employed/salaries } & $\mathrm{N}(\%)$ & $\mathrm{N}(\%)$ & \multirow{6}{*}{.855} & \multirow{6}{*}{1.335} & \multirow{6}{*}{4} \\
\hline & & $14(10.2 \%)$ & $22(7.6 \%)$ & & & \\
\hline & Farmers & $54(39.4 \%)$ & $127(44.1 \%)$ & & & \\
\hline & Business/Self employed & $33(24.1 \%)$ & $67(23.3 \%)$ & & & \\
\hline & Unemployed & $31(22.6 \%)$ & $63(21.9 \%)$ & & & \\
\hline & Others & $5(3.6 \%)$ & $9(3.1 \%)$ & & & \\
\hline \multirow[t]{8}{*}{ Monthly income (KSH) } & & $\mathrm{N}(\%)$ & $\mathrm{N}(\%)$ & \multirow{8}{*}{.020} & \multirow{8}{*}{14.970} & \multirow{8}{*}{6} \\
\hline & Less than 10,000 & $76(55.5 \%)$ & $205(71.2 \%)$ & & & \\
\hline & Between 10,000-20,000 & $34(24.8 \%)$ & $56(19.4 \%)$ & & & \\
\hline & Between 20,000-30,000 & $8(5.8 \%)$ & $11(3.8 \%)$ & & & \\
\hline & Between $30,000-40,000$ & $6(4.4 \%)$ & $5(1.7 \%)$ & & & \\
\hline & Between 40,000-50,000 & $6(4.4 \%)$ & $4(1.4 \%)$ & & & \\
\hline & Over 50,0000 & $5(3.6 \%)$ & $3(1 \%)$ & & & \\
\hline & None & $2(1.5 \%)$ & $4(1.4 \%)$ & & & \\
\hline
\end{tabular}




\begin{tabular}{|c|c|c|c|c|c|c|}
\hline Variable & & \multicolumn{2}{|c|}{ Dependent Variable } & \multicolumn{3}{|c|}{ Statistical Significance } \\
\hline \multirow[t]{2}{*}{ Social Demographic } & & Screened & Not Screened & $\mathrm{P}$ value & $X^{2}$ & df \\
\hline & & $\mathrm{N} \%$ & $\mathrm{~N} \%$ & \multirow{4}{*}{.071} & \multirow{4}{*}{5.287} & \multirow{4}{*}{2} \\
\hline \multirow[t]{3}{*}{ Age } & $18-34$ & $27(19.7 \%)$ & $74(25.7 \%)$ & & & \\
\hline & $35-60$ & $96(70.1 \%)$ & $169(58.7 \%)$ & & & \\
\hline & $60+$ & $14(10.2 \%)$ & $45(15.6 \%)$ & & & \\
\hline \multirow[t]{6}{*}{ Marital Status } & & $\mathrm{N}(\%)$ & $\mathrm{N}(\%)$ & \multirow{6}{*}{.677} & \multirow{6}{*}{2.318} & \multirow{6}{*}{4} \\
\hline & Single & $177(12.4 \%)$ & $29(10.1 \%)$ & & & \\
\hline & Married Monogamous & $96(70.1 \%)$ & $199(69.1 \%)$ & & & \\
\hline & Married Polygamous & $8(5.8 \%)$ & $14(4.9 \%)$ & & & \\
\hline & Divorced /Separated & $3(2.2 \%)$ & $13(4.5 \%)$ & & & \\
\hline & Widow & $13(9.5 \%)$ & $33(11.5 \%)$ & & & \\
\hline
\end{tabular}

\section{Journal of Biology, Agriculture and Healthcare}

\section{Discussion}

The study found out that the association between socio demographic characteristics (religion and monthly income) and TB screening was statistically significant. This implies that religion and monthly income of community members of Tigania East were associated with TB screening. Jewett et al., (2016) states that risk of exposure to TB in various social settings. Students can be more exposed to TB when volunteering, researching and travelling (Jewett et al., 2016). Medical students are at higher danger of exposure to TB and are required to do annual screening for TB.

In TB management gender plays an important role, as seen in various countries whereby men give better outcomes than women and the reverse in other countries (UNAIDS and Stop TB, 2016). Globally TB management focuses on early diagnosis and treatment of cases in high TB and HIV-endemic areas (WHO,2016). Nevertheless, low detection of TB and a rise of multi-drug-resistant strains have been a challenge (WHO,2016)

A study conducted by Esmael Ali, Agonafir , Desale, Yaregal\& Desta (2013) on assessment of patients' knowledge, attitude, and practice regarding pulmonary tuberculosis in eastern Amhara regional state, Ethiopia documented misconceptions ranging from $66.3 \%$ to $99.7 \%$ of the population on the aetiology (cause) of TB, $27.6 \%$ to $90.1 \%$ on the symptoms, $0.1 \%$ to $48.6 \%$ on the transmission and $33.4 \%$ to $92.9 \%$ on prevention methods (AmoAdjei \& Kumi-Kyereme,2013. Literacy status, socio-cultural differences, gender, and spatial variations have been reported to be factors affecting TB knowledge, attitude and practices (KAP) (Amo-Adjei , Kumi-Kyereme ;2013 ; Legesse, Ameni , Mamo , Medhin , Shawel , Bjune ,2010;Bati, Legesse , Medhin 2013)

\section{Conclusion and recommendation}

The study made the following conclusion; the association between socio demographic characteristics (religion and monthly income) and TB screening was statistically significant. This implies that the religion and monthly income of community members of Tigania East were associated with TB screening. The study recommend that Ministry of Health should introduce and implement Integrated Public health campaigns targeting all age groups, social class and literacy level in Meru community towards TB screening by health managers at lower administrative units

\section{Journal of Biology, Agriculture and Healthcare \\ References}

Amo-Adjei, J. and Kumi-Kyereme, A. (2013) "Myths and misconceptions about tuberculosis transmission in Ghana," BMC international health and human rights, 13(1), p. 38.

Assessing the tuberculosis (TB) screening compliance rates and treatment completion among international students at the University of Kentucky Theses and Dissertations--Public Health Malinga, P University of Kentucky,2019

Bati, J., Legesse, M. and Medhin, G. (2013) “Community's knowledge, attitudes and practices about tuberculosis in Itang Special District, Gambella Region, South Western Ethiopia,” BMC public health, 13(1), p. 734.

Esmael, A. et al. (2013) “Assessment of patients' knowledge, attitude, and practice regarding pulmonary tuberculosis in eastern Amhara regional state, Ethiopia: cross-sectional study," The American journal of tropical medicine and hygiene, 88(4), pp. 785-788.

Fisher, C. M. (2010) "Researching and Writing a Dissertation: An Essential Guide For Business Students." Harlow. Global Tuberculosis Report (2013) Who.int. Available at: https://www.who.int/teams/global-tuberculosisprogramme/tb-reports (Accessed: November 26, 2020).

Guest, G. S., MacQueen, K. M. and Namey, E. E. (2018) Applied Thematic Analysis. Thousand Oaks, CA: SAGE Publications.

Jewett, A. et al. (2016) "US college and university student health screening requirements for tuberculosis and 
vaccine-preventable diseases, 2012," Journal of American college health: J of ACH, 64(5), pp. 409-415.

Legesse, M. et al. (2010) "Knowledge and perception of pulmonary tuberculosis in pastoral communities in the middle and Lower Awash Valley of Afar region, Ethiopia," BMC public health, 10(1), p. 187.

"The prevalence of and reasons for interruption of anti-tuberculosis treatment by patients at Mbekweni Health Centre in the King SabataDalindyebo (KSD) District in the Eastern Cape province" (2014) South African Fam Pract.

UNAIDS and stop TB partnership report (2016) stoptb.org http://www.stoptb.org/assets/documents/resources/publications/acsm/Gender_Assessment_tool_tb_hiv_una ids_final_2016 eng.pdf

\section{Journal of Biology, Agriculture and Healthcare}

World Health Organization Global Tuberculosis report (2018). Who.int. https://www.who.int/tb/publications/global_report/gtbr2018_main_text_28Feb2019.pdf?ua\%20=\%201Gene va, 2014. (Accessed March 15, 2018 )

World Health Organization. Global tuberculosis report (2016)

https://apps.who.int/iris/bitstream/handle/10665/250441/9789241565394-eng.pdf?sequence=1

Geneva,Switzerland; 2016 